\title{
Focused Antinatal Care Service Utilization and Associated Factors Among Pregnant Women's in Shire, Tigray, Ethiopia
}

\author{
Berhane Fseha* and Gebrehiwot Gebremariam \\ Department of Public health, College of Medicine and Health science, Ethiopia \\ *Corresponding author: Berhane Fseha, Department of public health college of medicine and health science, Ethiopia
}

\begin{abstract}
ARTICLE INFO
Received: 慧 February 15, 2019

Published: 幽 February 28, 2019

Citation: Berhane Fseha*, Gebrehiwot Gebremariam. Focused Antinatal Care Service Utilization and Associated Factors Among Pregnant Women's in Shire, Tigray, Ethiopia. Biomed J Sci \& Tech Res 15(2)-2019. BJSTR. MS.ID.002686.
\end{abstract}

Abbreviations: ANC: Antenatal Care, FANC: focused antenatal care, ETB: Ethiopian Birr, HIV: Human Immuno Virus, OPD: Out Patient Department, SPSS: Statistical Package for Social Science

\begin{abstract}
Background: To decrease maternal mortality due to pregnancy and child birth complications antenatal care for mothers has remarkable role by creating good opportunity to counsel the mother about pregnancy danger signs, birth preparedness and health seeking behavior like institutional delivery. According to focused antenatal care every pregnant mother is at risk for complications and aims to make it safe the health of the mothers and their infants through evaluating, intervention and promotion for early detection and treatment of the complications. The main objective of this study was to assess the magnitude of focused antenatal care service utilization and its associated factors among pregnant mothers and Appling the current study result will increase the awareness of health professionals about the non-attendance of focused antenatal care service in the study area.
\end{abstract}

Methods: Cross-sectional study design was conducted, and single population proportion used sample size formula. A pre-tested structured questionnaire was used to collect data on focused antenatal care utilization and associated factors. The data was entered to SPSS version 20.0 software packages for analysis. Binary logistic regression analysis was conducted to identify the factors significantly associated.

Result: 284 mothers were included in the study on which $36.6 \%$ mothers attend focused antenatal care. The variables those significantly associate to utilization of focused antenatal care were marital status, source of information, knowledge of danger sign of pregnant mothers and waiting time.

Keywords: Antenatal care; Focused antenatal care; Utilization

\section{Introduction}

The outcome of pregnancy and child birth associated mortality in the world was 303,000 maternal mortality annually and majority (99\%) of them occurred in developing countries with sub-safaran Africa countries account for $66 \%$ of the maternal mortality due to pregnancy and child birth complications [1]. To decrease maternal mortality due to pregnancy and child birth complications antenatal care for mothers has remarkable role by creating good opportunity to counsel the mother about pregnancy danger signs, birth preparedness and health seeking behavior like institutional delivery [2]. According to focused antenatal care (FANC) every pregnant mother is at risk for complications and aims to make it safe the health of the mothers and their infants through evaluating, intervention and promotion for early detection and treatment of the complications [3]. The prevalence of pregnant mothers that attended focused antenatal care in Ethiopia showed dynamic change from time to time [4]. According to EDHS 2014 and EDHs 2016 result similar proportion of pregnant woman (32\%) attend four and above antenatal care visit to health institutions $[5,6]$. But there was great increment from EDHS 2011 result of focused antenatal care service visit [7]. The main objective of this study was to assess the magnitude of focused antenatal care service utilization and its associated factors among pregnant mothers and Appling the current study result will increase the awareness of health professionals about the non-attendance of focused antenatal care service in the study area. 


\section{Methods}

\section{Study Area and Period}

The study was conduct from January - February 2017 in shire governmental health institutions. Shire town which is located around $1087 \mathrm{Km}$ from Addis Ababa, capital city of Ethiopia and $305 \mathrm{~km}$ from Mekele, capital city of Tigray region. Shire town is bounded by laelay adiyabo woreda in the North, Asgedetsmbla woreda in the Western, Medebay Zana woreda in the East and Tselemti wored in the South. Based on 2015 estimation the woreda has a total population of 74,512, out of which 36511 (49\%) and 38001 (51\%) were male and female population respectively and the number of females at reproductive age (15-49 years) is 2533 out of this 1632 women are pregnant. The town is divided in to 5 kebeles, with regard to health infrastructure; there are 3 currently functional health centers and one general Hospital. There are one preparatory and two high school in the town.

Study Design: Facility based cross-sectional study was conducted.

Source Population: The source population were all pregnant women living in the town.

Study Population: The study population includes all pregnant women's that found in shire town during the study period

Study Unit: Pregnant mother was the study unite

\section{Inclusion criteria and Exclusion criteria}

Inclusion Criteria: All pregnant mothers visit to selected health facility during the study period and voluntary to give information at the time of data collection.

Exclusion Criteria: Critical ills mothers will be excluded from the study.

\section{Sample Size and Sampling Techniques}

Sample Size: The sample size was determined by using a formula for estimating a single population proportion. Prevalence is taken as $\mathbf{5 0 \%}$.

$$
n=\frac{\left(Z_{\alpha / 2}\right)^{2} p(1-p)}{d^{2}}
$$

Where $\mathrm{n}=$ estimated sample size

$\mathrm{z}=$ Confidence limit (1.96)

$\mathrm{P}=$ prevalence $(50 \%)$

$\mathrm{d}=$ marginal error $(5 \%)$

$\mathrm{n}=(1.96) 2 \times 0.5(1-0.5) /(0.05)^{2}=384$

Since the study population is less than 10,000 based on the finite population correction formula will be use

$n f \frac{n}{1+(n / N)}=\frac{384}{1+384 / 1102}$

Where $\mathrm{nf}=$ desired sample size

$\mathrm{n}=$ the calculated sample size

$\mathrm{N}=$ total population

$\mathrm{nf}=284$

\section{Sampling Techniques}

Systematic random sampling technique was used to select the study unit. By calculating $\mathrm{k}$ we gate three. Hence, every third pregnant mother who came for ANC service was included in the study. Sample Size determination frame work diagram (Figure 1).

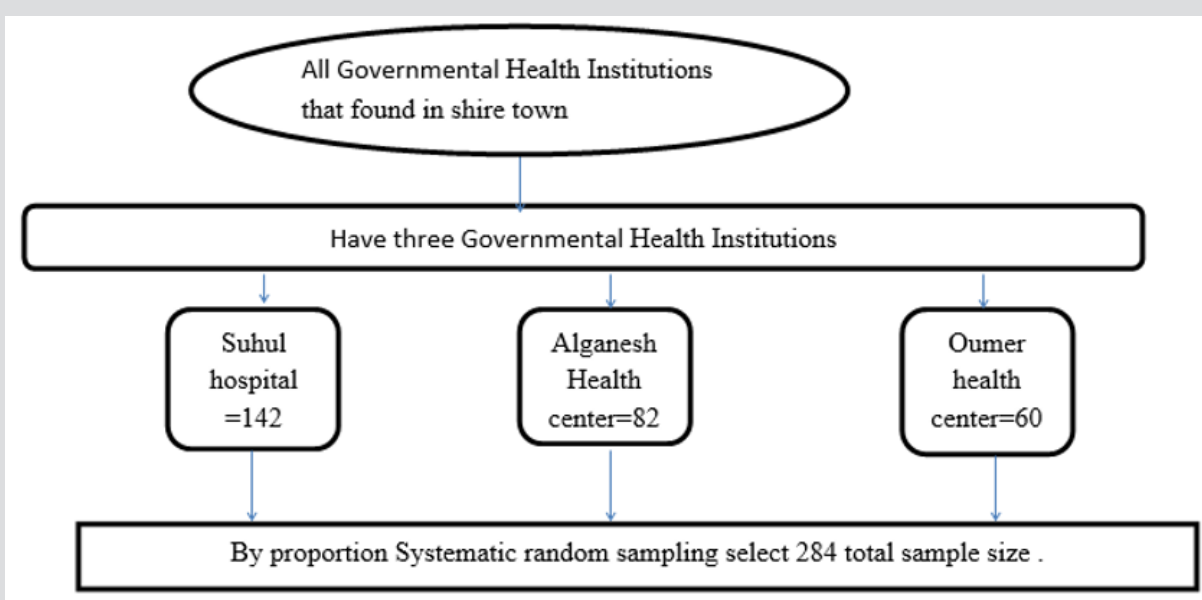

Figure 1: Sample Size determination frame work diagram.

\section{Variable}

Dependent variable

i) Focused Antenatal Care utilization.

ii) Independent variables

iii) Socio demographic variables (age of the mothers, marital status, place of residence, family income, educational status of the mothers, family size, occupation of the mother, religion,)

\section{Operational Definitions}

Antenatal Care: The care given to mothers during pregnancy by health professionals.

Good knowledge: those mothers who score mean value and above to questions asked on Focused Antenatal follow up service, advantages of these services, pregnancy and delivery related complications and mothers susceptible to these complications. 
Poor knowledge: those mothers who score below mean value to questions asked on Focused Antenatal follow up service, advantages of these services, pregnancy and delivery related complications and mothers susceptible to these complications.

Data collection Procedure: Data was collected by face-toface interview using a structured and pre-tested questionnaire. The questionnaire was prepared in English language. Three diploma nurse data collectors and 1-degree BSC nurse supervises that follow data collection process.

Data Quality Control: The quality of data was assured by proper designing and pre-testing. Training was given for data collectors and supervisors by the principal investigator for a day before and one day after pretest. The training was including discussion on the objectives of the study and on the contents of the questionnaire one by one, on procedures, and data collection techniques and on the issues of the confidentiality of the responses. Every day after data collection, questionnaires was reviewed and checked for completeness by the supervisors and principal investigator and the necessary feedback was offered to data collectors in the next morning.

Data Processing and Analysis: All the questionnaires were checked visually, coded and entered into SPSS version 20.0 software packages for analysis. For controlling errors $10 \%$ of the questionnaire was double enter and frequency checks also done. The data was analyzed using descriptive and inferential statistics to determine the effect of various factors on the outcome variable and to control confounding effect. Binary logistic regression analysis was applied to identify the variables significantly associated with

Table 1: Socio demographic characteristics of the study participants.

\begin{tabular}{|c|c|c|}
\hline Variable & Frequency & Percentage \\
\hline \multicolumn{3}{|l|}{ Age (yrs) } \\
\hline $15-19$ & 10 & 3.5 \\
\hline $20-24$ & 108 & 38 \\
\hline $25-29$ & 43 & 15.1 \\
\hline $30-34$ & 74 & 26.1 \\
\hline $35-39$ & 32 & 11.3 \\
\hline$>40$ & 17 & 6 \\
\hline \multicolumn{3}{|l|}{ Ethnicity } \\
\hline Amhara & 20 & 7 \\
\hline Kunama & 27 & 9.5 \\
\hline Tigray & 231 & 81.3 \\
\hline Other & 6 & 2.1 \\
\hline \multicolumn{3}{|l|}{ marital status } \\
\hline Marriied & 247 & 87 \\
\hline Divorced & 24 & 8.5 \\
\hline Widowed & 13 & 4.5 \\
\hline \multicolumn{3}{|l|}{ Educational status } \\
\hline Can't read \& write & 9 & 3.2 \\
\hline Read \& write & 25 & 8.8 \\
\hline Primary education & 98 & 34.5 \\
\hline Secondary education & 107 & 37.7 \\
\hline College and above & 45 & 15.8 \\
\hline
\end{tabular}

focused antenatal care utilization. The model fittnes was checked by hosmer and lemshow test goodness of fitness and multicollinearity was checked by variance inflation factor. The results were present in the form of tables, figures and text using frequencies and summary statistics such as mean, standard deviation and percentage to describe the study population in relation to relevant variables.

Ethical Consideration: The proposal was review and approved by the Institutional Review Board of Soloda health and Technology college and permission to conduct this study was also obtain from shire woreda Health Office. All selected participants were communicated about the study in order to obtain their written consent before administering questionnaires. Participants were also informed that they had the full right to discontinue or refuse to participate in the study.

\section{Dissemination of Results}

The finding of this study will disseminate to different governmental and nongovernmental organizations working on FANC including Woreda health office. Moreover, the finding of the study will be present in the regional and national workshops and will be sent to national and international journals for publication.

\section{Results}

\section{Socio-Demographic Characteristics of the Respondent}

From the total study participants $38 \%$ were $20-28$ years age group, $81.3 \%$ were Tigray in ethnicity, $87 \%$ were married in their marital status, $37.7 \%$ attend secondary education and more than half (55.3\%) were house wife in occupation (detail Table 1). 


\begin{tabular}{|c|c|c|}
\hline Occupation & & 55.3 \\
\hline House wife & 157 & 8.1 \\
\hline Maid servant & 23 & 19.4 \\
\hline Civil servant & 55 & 13.7 \\
\hline Merchant & 39 & 3.5 \\
\hline Student & 10 & 27.5 \\
\hline Number of pregnancies & & 24.6 \\
\hline One & 78 & 22.9 \\
\hline Two & 70 & 18 \\
\hline Three & 65 & 7 \\
\hline Five & 51 & \\
\hline Six & 20 & \\
\hline Religion & & \\
\hline Orthodox & 181 & 1.8 \\
\hline Protestant & 5 & 33.1 \\
\hline Muslim & 94 & 1.4 \\
\hline Other & 4 & \\
\hline
\end{tabular}

Obstetric Characteristics and Respondent's knowledge pregnancy. 91.9\% of the get information about ANC from health on FANC Utilization

Majority $(82.7 \%)$ of the study participants had planned institution, more than half (58.1\%) know the befits of ANC correctly, and $63.7 \%$ of the get ANC service at their 4-6 gestational age of the fetus (detailed Table 2).

Table 2: Obstetric characteristics and Respondent's knowledge on ANC utilization of pregnant mothers, 2017.

\begin{tabular}{|c|c|c|}
\hline variable & Frequency & Percentage \\
\hline \multicolumn{3}{|c|}{ Did you plan the pregnancy } \\
\hline No & 49 & 17.3 \\
\hline Yes & 235 & 82.7 \\
\hline \multicolumn{3}{|l|}{ Source of information } \\
\hline Health institution & 261 & 91.9 \\
\hline TBA & 3 & 1.1 \\
\hline Relative/ friend & 20 & 7 \\
\hline \multicolumn{3}{|l|}{ Benefits of ANC } \\
\hline Maternal health & 72 & 25.4 \\
\hline Child health & 43 & 15.1 \\
\hline Both maternal \& child & 165 & 58.1 \\
\hline Don't know & 4 & 1.4 \\
\hline \multicolumn{3}{|l|}{ Attend ANC } \\
\hline No & 3 & 1.1 \\
\hline Yes & 281 & 98.9 \\
\hline \multicolumn{3}{|l|}{ At what gestational age } \\
\hline \multicolumn{3}{|l|}{ 1-3 month } \\
\hline 4-6 month & 74 & 26.1 \\
\hline \multirow[t]{2}{*}{ 7-9 month } & 181 & 63.7 \\
\hline & 19 & 10.2 \\
\hline
\end{tabular}

\section{Fanc Service Utilization of The Study Participants}

Among mothers who attained ANC for their last pregnancy,
$100(35.2 \%)$ attained 3 times, $104(36.6 \%)$ attained four and more times, whereas $28(9.9 \%)$ and $52(18.3 \%)$ attained one and two times respectively (Figure 2). 


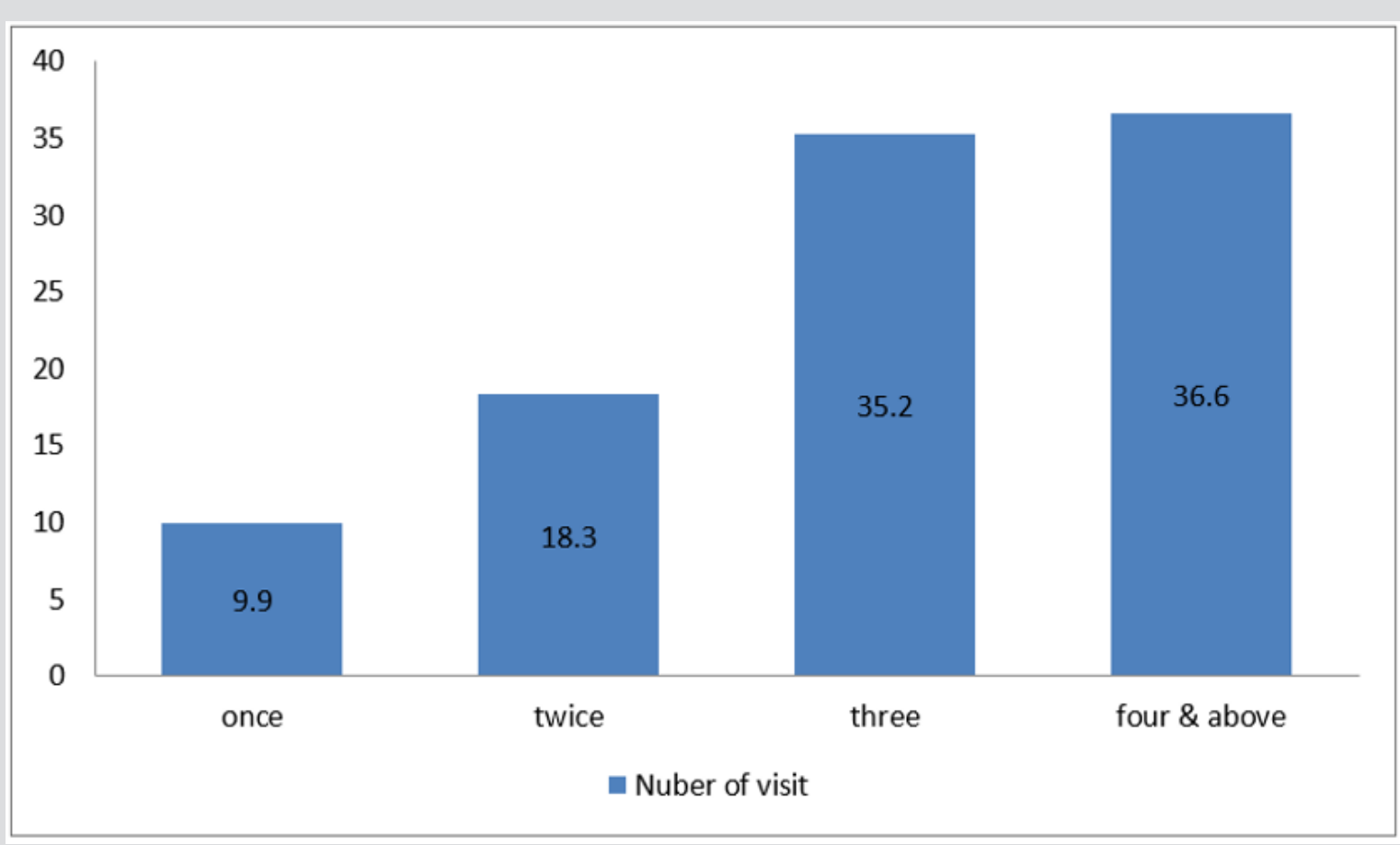

Figure 2: Graph showing the number of visits of pregnant mothers to get ANC service.

\section{Factors Associated with Focused ANC}

Binary logistic regression model has been applied in the current study to identify the independent variables significantly associated with the focused antenatal care utilization because of the dependent variable was dichotomous. Hosmer and lemshow test were check for model fitness and multicollinearity was checked by variance inflation factor. The independent variables with $\mathrm{p}$-value less than 0.25 in the bivariate logistic regression have been transferred to multivariate logistic regression to identify the significantly associated variable with less than $0.05 \mathrm{p}$-value. In the multivariate logistic regression, the variables Marital status, knowledge on danger signs of pregnant mother, source of information and waiting time to get ANC service at the health institution were significantly associated with focused antenatal care utilization with p-value less than 0.05 . Mothers who were married were more likely to attend focused antenatal care than mothers who were widowed or divorce (AOR $(95 \% \mathrm{CI})=2.24(1.15,3.14$, $\mathrm{p}$ - value $=<0.001)$. and Mothers who were who have knowledge on danger signs of pregnant mother were more likely to attend focused antenatal care as compared to those who have no knowledge on the danger signs (AOR (95\%CI) $=3.09$ (1.16,2.88), p- value=0.008). Detail Table 3 .

Table 3: Factors associated with mother's attend focused ANC.

\begin{tabular}{|c|c|c|c|c|}
\hline \multirow[t]{2}{*}{ Variable } & \multicolumn{2}{|c|}{ Focused ANC } & \multirow[t]{2}{*}{ AOR( $95 \% \mathrm{CI})$} & \multirow[t]{2}{*}{ p-value } \\
\hline & Yes & No & & \\
\hline \multicolumn{5}{|c|}{ Marital status } \\
\hline Married & 247 & 0 & $2.24(1.15,3.14)$ & $<0.001^{*}$ \\
\hline widowed/divorce & 34 & 3 & 1 & \\
\hline \multicolumn{5}{|c|}{ Educational Status } \\
\hline Can't read & 9 & 0 & 1 & \\
\hline Read \& write & 25 & 0 & $1.11(0.45,2.34)$ & 0.218 \\
\hline 1o education & 95 & 3 & $1.71(0.01,6.11)$ & 0.247 \\
\hline 2o education & 107 & 0 & $1.32(0.16,3.33)$ & 0.351 \\
\hline College \&above & 45 & 0 & $1.82(0.45,3.34)$ & 0.421 \\
\hline \multicolumn{5}{|c|}{ Occupation } \\
\hline House wife & 154 & 3 & 1 & \\
\hline Maid servant & 23 & 0 & $2.22(0.89,4.81)$ & 0.653 \\
\hline Civil servant & 55 & 0 & $1.64(0.08,1.19)$ & 0.513 \\
\hline Merchant & 39 & 1 & $1.57(0.05,3.44)$ & 0.241 \\
\hline Student & 10 & 0 & $2.55(0.11,5.51)$ & 0.712 \\
\hline
\end{tabular}




\begin{tabular}{|c|c|c|c|c|}
\hline \multicolumn{5}{|c|}{ Knowledge on danger sign } \\
\hline yes & 196 & 3 & $3.09(1.16,2.88)$ & $0.008^{*}$ \\
\hline No & 82 & 3 & 1 & \\
\hline \multicolumn{5}{|c|}{ Source of information } \\
\hline Health institution & 259 & 2 & $3.55(1.59,3.97)$ & $0.009^{*}$ \\
\hline TBA & 2 & 1 & $1.72(1.85,4.35)$ & 0.014 \\
\hline Friends & 18 & 2 & 1 & \\
\hline \multicolumn{5}{|c|}{ Planned pregnancy } \\
\hline Yes & 232 & 3 & $0.632(0.57,5.74)$ & 0.471 \\
\hline No & 47 & 2 & 1 & \\
\hline \multicolumn{5}{|c|}{ Benefit of ANC } \\
\hline Know & 164 & 1 & $2.764(0.09,2.91)$ & 0.382 \\
\hline Does not know & 117 & 2 & 1 & \\
\hline \multicolumn{5}{|c|}{ waiting time } \\
\hline$\leq 30$ minutes & 209 & 0 & $2.449(01.94,4.62)$ & $0.004^{*}$ \\
\hline >30 minute & 72 & 3 & 1 & \\
\hline
\end{tabular}

\section{Discussion}

This health facility based cross-sectional study tried to assess the focused antenatal care service utilization and associated factors in North West Tigray, Ethiopia. According to the WHO recommendation, for normal pregnancy woman should receive four ANC visits during pregnancy [8]. The current study result showed that focused antenatal care service utilization was $36.6 \%$. This study finding is consistent with a study conducted in debretawor town with utilization rate of 35.3\% [10] and with the DHS 20116 in Ethiopia in, which showed that women received focused antenatal care only about $32 \%$ [5]. But this study was not in line with a study conducted in sidama zone which is $76.5 \%$ [9] and with a study conducted in jimma zone which is $60.4 \%$ [11].

This study was to identify a number of factors that have important influences on utilization of focused antenatal care service it reviled marital status, source of information, knowledge on danger signs of pregnant mother and waiting time to get FANC service were found significantly associated with utilization of ANC services.

In this study showed that marital status was significantly associated with utilization of focused antenatal care service. Since the vast majority of the study subjects $(87 \%)$ were married. This study is consistent with study conducted the other studies done in harari region reviled while single \divorced women were found to be more likely to be non-attendances as compared to with married women [12]. Source of information is found to be significantly affecting the utilization of focused antenatal care service. Pregnant women who were source of information more likely to attend focused antenatal care as compared to those who heard for relatives to utilization of focused antenatal care service. The result of this study is in line with study done in south Ethiopia [9]. From this study it was observed that pregnant women who know danger Signs of pregnancy more likely to attend focused antenatal care service as compared to those mothers who were not know danger Signs of pregnancy to utilization of focused antenatal care service This finding is reline with other studies, which indicated that women's are more likely to experienced concern about any health problems were more likely to be ANC User. In this study most of respondents could able to name the acceptable danger Signs of pregnancy [11].

\section{Conclusion}

Focused antenatal care service utilization was found to be low and distribution varied among the different socio-demographic and obstetric factor. Factors identified as significantly associated with focused antenatal care utilization were marital status, source of information, knowledge on danger signs of pregnant mother and waiting time to get FANC service.

\section{Limitation}

This study had some limitations:

a) It is cross-sectional study, and so the temporal relationship between utilization of focused antenatal care and independent variables cannot be assured.

b) Social desirability bias.

\section{Declarations}

\section{Ethics approval and consent to participate}

The proposal was review and approved by the Institutional Review Board of Soloda health and Technology college and permission to conduct this study was also obtain from shire woreda Health Office. All selected participants were communicated about the study in order to obtain their written consent before administering questionnaires. Participants were also informed that they had the full right to discontinue or refuse to participate in the study.

Consent for publication: Not applicable

Availability of data and material

a) All data generated or analyzed during this study are included in this published article and its supplementary information files. 
b) The datasets used and/or analyzed during the current study are available from the corresponding author on reasonable request.

\section{Competing interests}

The authors declare that they have no competing interests

\section{Authors contributions}

$\mathrm{BF}$ participated in the preparation of the proposal, design of the study, data analysis and present the data, preparing daft of the manuscript and critically reviewing. Similarly, SG participated in the design of the study, data analysis and presentation, reviewing of the manuscript. Both authors read, accepted and approved the final manuscript

\section{Acknowledgement}

we would like to thank health professional working in the health center for their cooperation in supplying me with necessary information and document during data collection. And, we acknowledge all study participants

\section{References}

1. Bongaarts J (2016) WHO, UNICEF, UNFPA, World Bank Group, and United Nations population division trends in maternal mortality: 1990 to 2015. Popul Dev Rev 42(4): 726.

2. World HO (1996) Mother-baby package: implementing safe motherhood in countries: practical guide. 1996.

\section{ISSN: 2574-1241}

DOI: 10.26717/BJSTR.2019.15.002686

Berhane Fseha. Biomed J Sci \& Tech Res

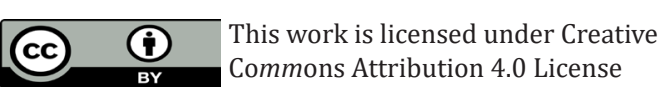

Submission Link: https://biomedres.us/submit-manuscript.php
3. Villar J (2001) WHO antenatal care randomized trial for the evaluation of a new model of routine antenatal care. Lancet 357(9268): 1565-1570.

4. Lincetto O, Mothebesoane-Anoh S, Gomez P, Munjanja S (2006) Antenatal care. Opportunities for Africa's newborns: practical data, policy and programmatic support for newborn care in Africa. 2006: 55-62.

5. Central SAAA (2016) Ethiopia Demographic and Health Survey 2016. Key indicator report. The DHS Program. Rockville: ICF; 2016.

6. Central SAE (2014) Ethiopia Mini Demographic and Health Survey 2014. Addis Ababa: Central Statistical Agency.

7. Demographic CE (2016) Health survey-2011. Addis Ababa and Calverton: Central Statistical Agency. ICF International.

8. Villar J (2001) WHO antenatal care randomized trial for the evaluation of a new model of routine antenatal care. Lancet 357(9268): 1565-1570.

9. D Dubale, D Deresse, W Negash (2017) Antenatal Care Utilization and Its Associated Factors among Pregnant Women in Boricha District, Southern. Diversity and Equality in Health and Care 14(2): 76-84.

10. Ayalew W, Nigatu M (2018) Focused antenatal care utilization and associated factors in Debre Tabor Town, northwest Ethiopia. BMC Research Notes 11: 819.

11. Chemir, Alemseged F, Workneh D (2014) Satisfaction with focused antenatal care service and associated factors among pregnant women attending focused antenatal care at health centers in Jimma town, Jimma zone, South West Ethiopia; a facility based cross-sectional study triangulated with qualitative study. BMC Research Notes 2014 7: 164.

12. Shemsedin SM (2009) Assessment of factor affecting the utilization of antenatal care and delivery services in Hareri region; in Ethiopia. 